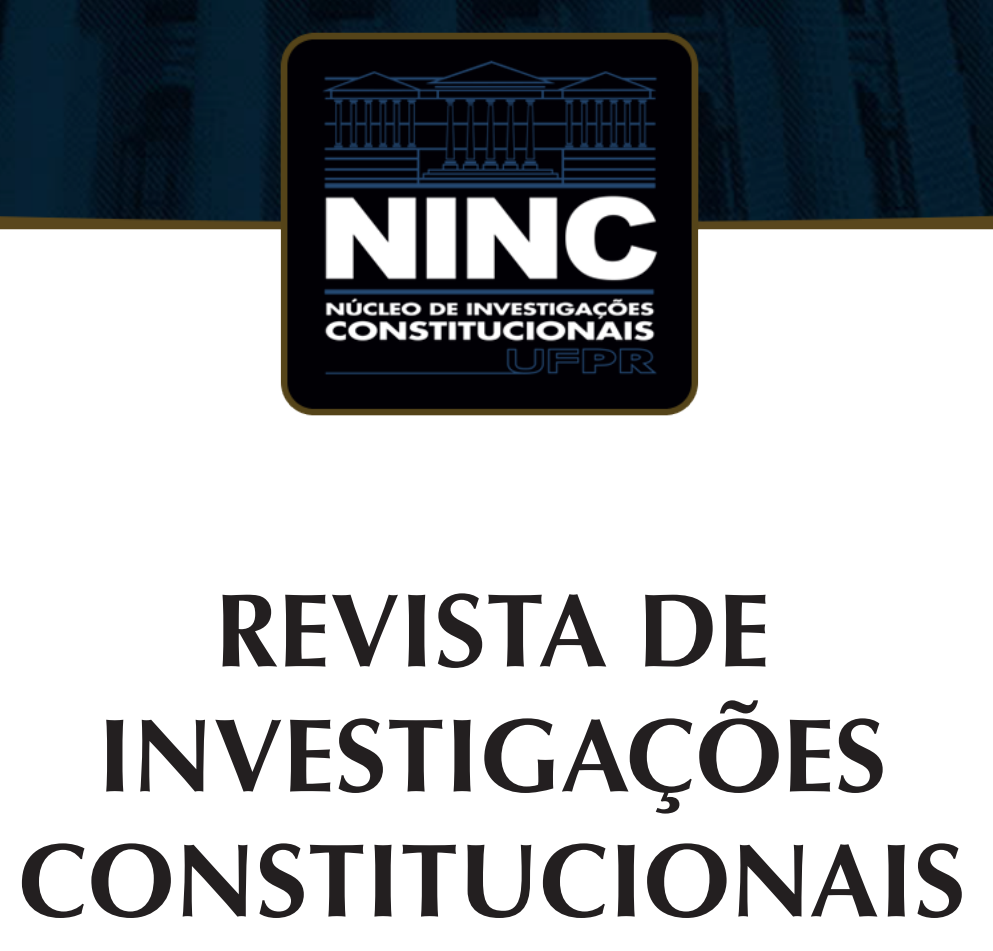

JOURNAL OF CONSTITUTIONAL RESEARCH

vol. 5 | n. 1 | janeiro/abril 2018 | ISSN 2359-5639 | Periodicidade quadrimestral Curitiba | Núcleo de Investigações Constitucionais da UFPR | www.ninc.com.br 


\title{
Los mecanismos de control constitucional aplicados a los actos administrativos en el Derecho Mexicano
}

\section{Constitutional control mechanisms applied to administrative acts in Mexican Law}

\author{
LUIS JOSÉ BÉJAR RIVERA* \\ Universidad Panamericana (México) \\ http://orcid.org/0000-0002-1898-527X \\ ljbejar@up.edu.mx \\ RODRIGO SALAZAR MUÑOZ** \\ Universidad Panamericana (México) \\ http://orcid.org/0000-0001-9187-3226 \\ rsalazar@salazaryasociados.com.mx
}

Recebido/Received: 25.10.2017 / October 25th, 2017 Aprovado/Approved: 30.12.2017 / December 30th, 2017

Resumen

El objeto de este trabajo es identificar al acto administrativo y sus elementos esenciales y cómo éstos pueden identificar un fundamento constitucional, de tal forma, que cuando se aplican los diversos mecanismos de control constitucional en el derecho mexicano, encontramos la forma en la cual se ejerce el control constitucional de los actos administrativos, más allá del llamado control de la legalidad administrativa y, cómo es que dichos controles constitucionales se desenvuelven ante la autoridad administrativa, la autoridad jurisdiccional o el juez judicial.

Palabras-clave: acto administrativo; control constitucional; Constitución; constitucionalidad; México.
Abstract

The purpose of this paper is to identify the administrative decisions and its essential elements and how they can be identified on a constitutional basis, hence, how is it the various mechanisms of constitutional control in Mexican law are applied; in which way are exercised the constitutional control of administrative decisions, beyond the so-called control of administrative legality, and how such constitutional controls are carried out before the administrative authority, the administrative tribunal or the judicial judge.

Keywords: administrative act; constitutional control; Constitution; constitutionality; Mexico.

Como citar esse artigo/How to cite this article: BÉJAR RIVERA, Luis José; SALAZAR MUÑOZ, Rodrigo. Los mecanismos de control constitucional aplicados a los actos administrativos en el Derecho Mexicano. Revista de Investigações Constitucionais, Curitiba, vol. 5, n. 1, p. 41-62, jan./abr. 2018. DOI: 10.5380/rinc.v5i1.56035.

*Profesor Investigador de la Universidad Panamericana - Facultad de Derecho (Augusto Rodin, 498, Ciudad de México, 03920, México). Doctor en Derecho y Maestro en Ciencias Jurídicas por la Universidad Panamericana, Campus México. Licenciado en Derecho por el ITESO. Miembro del Sistema Nacional de Investigadores del CONACYT. Visiting Research Fellow de la Facultad de Derecho de la Universidad de Montreal. E-mail: ljbejar@up.edu.mx.

** Profesor de la Universidad Panamericana - Facultad de Derecho (Augusto Rodin, 498, Ciudad de México, 03920, México). Doctor en Derecho, Maestro en Ciencias Jurídicas, Maestro en Derecho Administrativo y Licenciado en Derecho por la Universidad Panamericana, Campus México. Profesor de la Universidad la Salle, Campus México. Asociado al Foro Iberoamericano de Derecho Administrativo. E-mail: rsalazar@salazaryasociados.com.mx. 


\section{SUMARIO}

1. Introducción; 2. El acto administrativo y sus elementos; 3. El fundamento constitucional del acto administrativo; 4. Los mecanismos de control constitucional del acto administrativo; 5. Conclusiones; 6. Referencias.

\section{INTRODUCCIÓN}

Históricamente, en el derecho mexicano, el control constitucional de los actos de autoridad ha jugado un papel preponderante. De hecho, mucho tiempo antes de la existencia de las jurisdicciones contencioso-administrativas en nuestro sistema, ya se encontraba claramente establecido el papel que el Juicio de Amparo, como instrumento de control constitucional por excelencia, tenía y tiene en México.

Aún más, de hecho, durante mucho tiempo, prácticamente a lo largo del todo el siglo XIX no se contó con un sistema de contencioso administrativo, debido a la inclinación judicialista de nuestro modelo constitucional ${ }^{1}$ y que históricamente ha sido sostenido. Adicionalmente, precisamente el modelo de amparo que se había venido desarrollando a lo largo de los años generó (si acaso recientemente empieza a tener algún cambio) un control concentrado de constitucional de los actos de autoridad, por ende, incluidos los actos administrativos.

Con la promulgación de la Ley Federal de Procedimiento Administrativo se emperazon a generar las bases para un desarrollo de las instituciones jurídico-administrativas (no es que no existiesen antes, pero en cuanto a su control, estaba prácticamente en manos del juicio de amparo) y pocos años después, con la ampliación de la competencia sobre la materia administrativa al entonces Tribunal Fiscal de la Federación (hoy, Tribunal Federal de Justicia Administrativa), el cual se encuentra fuera del Poder Judicial, destacando así, nuestro sistema dualista.

En este trabajo expondremos las reglas del modelo mexicano de control constitucional de los actos administrativos, teniendo como punto de partida a los elementos del acto administrativo y la forma en que constitucionalmente pueden ser valorados por nuestros jueces, sean jurisdiccionales o judiciales.

Además, analizaremos los fundamentos que, la Constitución Política de los Estados Unidos Mexicanos consagra en relación los actos administrativos, teniendo como punto de partida, que dicho ordenamiento simplemente los alude como actos de autoridad.

\footnotetext{
1 Sobre este particular, Cfr. BÉJAR RIVERA, Luis José. La dualidad jurisdiccional en materia administrativa en México. In: RODRÍGUEZ-ARANA MUÑOZ, Jaime; VÁZQUEZ IRIZARRY, William; RODRÍGUEZ MARTÍN-RETORTILLO, María, (Coords.) Contenciosos administrativos en Iberoamérica. t. I. San Juan: Universidad de Puerto Rico, 2015.
} 
Por último, mostraremos el comportamiento de los mecanismos de control constitucional sobre los actos administrativos, haciendo la valoración correspondiente respecto de su prospección.

Finalmente, resulta importante destacar que el presente trabajo no es exhaustivo, al ser imposible agotar la totalidad de los temas que se abordan durante este trabajo. Por ello, hemos optado por concentrar la mayor información posible, pero, en más de algún caso, la hemos obviado, para facilitar el acercamiento al mismo.

Con nuestra investigación pretendemos mostrar las principales generalidades sobre la operatividad del control constitucional sobre la institución jurídica del acto administrativo, dentro del derecho mexicano, mostrando sus limitantes y retos, al igual que su comportamiento.

\section{EL ACTO ADMINISTRATIVO Y SUS ELEMENTOS}

Sin duda, uno de los grandes pilares del derecho administrativolo constituye la categoría del acto administrativo. A partir de él, la Administración Pública decide sobre una situación jurídico-administrativa que provoca la afectación de los administrados.

El acto administrativo se convierte en un mecanismo de previsibilidad de la actuación administrativa, así como su estricto apego a derecho. Aún en sistemas anglosajones, donde la categoría de acto administrativo goza de amplia flexibilidad, se considera la existencia de una decisión administrativa que regula una multiplicidad de situaciones en diferentes sectores en pos del interés general2.

En términos generales y sin pretender introducirnos en el debate sobre la conceptualización del acto administrativo, para efectos de este trabajo, partimos del entendimiento de esta institución consiste en la manifestación unilateral de la voluntad administrativa que crea consecuencias jurídicas concretas sobre un particular, en ejercicio de una potestad de derecho administrativo.

Todo acto administrativo se integra por un conjunto de elementos esenciales, que varían de acuerdo a la postura doctrinal que se adopte, como sostiene el profesor argentino Miguel S. Marienhoff, quien menciona que: "En el terreno doctrinario hay gran desconcierto en lo atinente a los 'elementos' del acto administrativo. No sólo los tratadistas no están de acuerdo acerca de cuáles son dichos elementos, sino que tampoco lo están acerca del significado de algunos de ellos. Del mismo modo, no siempre un mismo elemento es denominado de la misma manera [...]"3

Reiteramos que el debate es amplio respecto 4 de los elementos del acto administrativo y que no es nuestro deseo agotarlo en este trabajo. Sobre el particular, nos

\footnotetext{
2 Al respecto, Cfr. GARANT, Patrice. Droit administratif. 6. ed. Cowansville: Éditions Yvon Blais, 2010. p. 160-161.

3 MARIENHOFF, Miguel S. Tratado de derecho administrativo. t. Il. 4. ed. Buenos Aires: Abeledo-Perrot, 2003. p. 249 y 250.

4 Sobre este particular, Cfr. BÉJAR RIVERA, Luis José. El acto administrativo y su finalidad. Ciudad de México: Porrúa, 2016.
} 
limitaremos a mencionar que nos hemos decantado por la postura de los profesores españoles Eduardo Gamero Casado y Severiano Fernández Ramo5, quienes distinguen cuatro elementos esenciales: a) Elemento Subjetivo, b) Elemento Objetivo, c) Elemento Formal y, d) Elemento Teleológico.

Los anteriores elementos se encuentran íntimamente vinculados a la validez y eficacia6 del acto administrativo. No obstante, consideramos que limitar la idea de los elementos del acto a su validez puede provocar un reduccionismo, que sea incapaz de plasmar su esencia.

En cuanto al primero de los elementos del acto administrativo, el elemento subjetivo, destacamos que existe consenso doctrinal respecto de que éste elemento descansa, de manera primordial, en la Administración Público como sujeto emisor y ejecutor del acto? .

Es por ello que, de manera frecuente, el elemento subjetivo del acto administrativo depende de las características de la competencia de la Administración. Al respecto, el profesor mexicano Gabino Fraga señala que: "La amplitud de la función administrativa impone por una parte la necesidad de crear múltiples órganos que se caracterizan por ser esferas especiales de competencia, y por otra parte, por requerir de personas físicas que ejerciten esa competencia."8

La competencia de la Administración debe estar prevista en el conjunto de normas objetivas que otorguen potestades para actuar a los funcionarios, entre las que se encuentran la Constitución, la ley y las normas reglamentarias. Al respecto, Gamero Casado y Fernández Ramos señalan: "el órgano que debe dictar el acto se encuentra establecido en las normas atributivas de las competencias administrativas [...] requiere de una norma atributiva concreta y sólo podrá alterarse el ejercicio de la competencia por los mecanismos ya conocidos: delegación, avocación, sustitución, etc."9

De la mano de la competencia, o mejor dicho, como parte de un ejercicio adecuado de la competencia por parte del funcionario público, se entiende que éste debe estar debidamente investido para ejercer el cargo, cerciorándose además de que el depósito de la potestad pública corresponda adecuadamente con la persona idónea para ello10.

\footnotetext{
5 GAMERO CASADO, Eduardo; FERNÁNDEZ RAMOS, Severiano. Manual Básico de Derecho Administrativo. Madrid: Tecnos, 2008. p. 337 y sigs.

6 Cfr. ROLDÁN XOPA, José. Derecho Administrativo. Ciudad de México: Oxford University Press, 2008. p. 15.

7 Esta posición es sostenida por autores como Nava Negrete y Pérez Dayán, quienes centran esta distinción en el aspecto organicista de la Administración. Sobre este particular, Cfr. NAVA NEGRETE, Alfonso. Derecho administrativo mexicano. 2. ed. Ciudad de México: FCE, 2001. p. 354; también: Cfr. PÉREZ DAYÁN, Alberto. Teoría General del Acto Administrativo. Ciudad de México: Porrúa, 2003. p. 108

8 FRAGA, Gabino. Derecho Administrativo. 28. ed. Ciudad de México: Porrúa, 1989. p. 122.

9 GAMERO CASADO, Eduardo; FERNÁNDEZ RAMOS, Severiano. Manual Básico de Derecho Administrativo. Madrid: Tecnos, 2008. p. 377.

10 Este punto está plenamente ilustrado por la Tesis Aislada P. XLVIII/2005, emitida por el Pleno de la Suprema Corte de Justicia
} 
Sin embargo, aunque parece una obviedad, dentro del elemento subjetivo se halla el sujeto pasivo del mismo: el administrado. A él es a quien se dirige el acto administrativo y es quien recibe los efectos jurídicos de la decisión de la autoridad administrativa, plasmados en el acto.

Con lo narrado se demuestra que, el elemento subjetivo se integra, por una parte, por la Administración Pública, como sujeto activo que emite o ejecuta el acto; $y$, por otra parte, por el administrado, como sujeto que recibe las consecuencias jurídicas del acto, como un sujeto pasivo en la relación que se desprende del acto administrativo.

En otro orden de ideas, el objeto o el elemento objetivo del acto administrativo, en palabras del profesor español Fernando Garrido Falla, es: "[...] el efecto práctico que con dicho acto se pretende obtener [...]"11.

Complementando lo anterior, Marienhoff señala que hablar del objeto del acto es sinónimo de contenido, es decir: "[...] medida concreta que mediante el acto adopta la autoridad, siendo ello lo que diferencia a un acto de otro acto. De modo que 'contenido' del acto es lo que éste preceptúa; es el efecto práctico que el sujeto emisor se propone lograr a través de su acción voluntaria; es en fin, lo que por dicho acto se dispone."12

En términos generales, la doctrina 13 ha sido consistente en referir que, el objeto del acto debe ser: a) lícito, b) posible y, c) cierto. Al respecto, entendemos: por lícito, que

de la Nación. SEMANARIO JUDICIAL DE LA FEDERACIÓN. México. Novena Época. Tomo XXII. Noviembre de 2005. p. 5, que señala textualmente:

“SERVIDORES PÚBLICOS. NO PUEDEN, VÁLIDAMENTE, CONOCER DE SU LEGITIMIDAD LOS TRIBUNALES DE AMPARO NI LOS ORDINARIOS DE JURISDICCIÓN CONTENCIOSA ADMINISTRATIVA.- La noción de "incompetencia de origen" nació para significar los problemas que entrañaban la ilegitimidad de las autoridades locales por infracciones a las normas reguladoras de su designación o elección. Dicha incompetencia se distinguía de las irregularidades examinadas en el contexto de control de legalidad de los actos de autoridad, porque su conocimiento por los tribunales federales se traduciría en una intervención injustificada en la soberanía de las entidades federativas, y redundaría en el empleo del juicio de amparo como instrumento para influir en materia política. Sin embargo, la referida noción, limitada al desconocimiento de autoridades locales de índole política o judicial, se hizo extensiva a todos los casos en que por cualquier razón se discutiera la designación de un funcionario federal o local perteneciente, inclusive, al Poder Ejecutivo, o la regularidad de su ingreso a cualquier sector de la función pública, introduciéndose una distinción esencial entre la incompetencia de origen y la incompetencia derivada del artículo 16 de la Constitución Política de los Estados Unidos Mexicanos, de lo que derivó que frente a los funcionarios de jure, se creó una teoría de los funcionarios de facto, es decir, aquellos cuya permanencia en la función pública es irregular, ya sea por inexistencia total o existencia viciada del acto formal de designación, o por ineficacia sobrevenida del título legitimante, frecuentemente debida a razones de temporalidad e inhabilitación. Ahora bien, el examen de la legitimidad de un funcionario y de la competencia de un órgano supone una distinción esencial, pues mientras la primera explica la integración de un órgano y la situación de una persona física frente a las normas que regulan las condiciones personales y los requisitos formales necesarios para encarnarlo y darle vida de relación orgánica; la segunda determina los límites en los cuales un órgano puede actuar frente a terceros. En ese sentido, el indicado artículo 16 no se refiere a la legitimidad de un funcionario ni a la manera como se incorpora a la función pública, sino a los límites fijados para la actuación del órgano frente a los particulares, ya que son justamente los bienes de éstos el objeto de tutela del precepto, en tanto consagra una garantía individual, y no un control interno de la organización administrativa. Por tanto, los tribunales de amparo ni los ordinarios de jurisdicción contenciosa administrativa federal pueden conocer, con motivo de argumentos sobre incompetencia por violación al artículo 16 constitucional, de la legitimidad de funcionarios públicos, cualquiera que sea la causa de irregularidad alegada, sin perjuicio de la posible responsabilidad administrativa o penal exigible a la persona sin investidura o dotada de una irregular."

11 GARRIDO FALLA, Fernando. Tratado de Derecho Administrativo. v. I. 13. ed. Madrid:Tecnos, 2002. p. 595.

12 MARIENHOFF, Miguel S. Tratado de derecho administrativo. t. II. 4. ed. Buenos Aires: Abeledo-Perrot, 2003. p. 272.

13 Cfr. GAMERO CASADO, Eduardo; FERNÁNDEZ RAMOS, Severiano. Manual Básico de Derecho Administrativo. Madrid: Tecnos, 2008. p. 378; MARIENHOFF, Miguel S. Tratado de derecho administrativo. t. Il. 4. ed. Buenos Aires: Abeledo-Perrot, 2003. p. 
el acto administrativo esté ajustado plenamente a las normas de las cuales emana; por posible, que el acto sea viable fácticamente, es decir, que no sea contrario a la naturaleza de las cosas o de las situaciones; $y$, finalmente, por cierto, que el acto tenga un objeto claro, determinado o determinable ${ }^{14}$.

A propósito del objeto del acto administrativo, Juan Carlos Cassagne señala que:

Si se trata de una actividad reglada, el objeto del acto administrativo aparecerá predeterminado por la norma, mientras en el supuesto de que fuera consecuencia del ejercicio de facultades discrecionales, aun cuando la Administración disponga de un amplio margen de libertad para emitir el acto, el objeto del mismo debe adaptarse al marco general normativo y al principio de legitimidad. 15

Por lo anterior es que, el objeto de todo acto administrativo descansa en aquello que le da su individualidad e identificación respecto del resto de actos administrati$\operatorname{vos}^{16}$. Por ello, podemos señalar que el objeto del acto administrativo constituye a su vez, su propio contenido, que se conforma, Fernando Garrido Falla17, de tres subelementos: a) natural, b) implícito y, c) eventual.

El contenido natural se refiere al mínimo indispensable que distingue al acto administrativo del efecto específico concreto que se busca sobre un particular, en concreto. En palabras de Juan Alfonso Santamaría Pastor, refiere a la tipicidad del acto administrativo o a la inclusión de la medida permitida por la norma atributiva de la potestad que se ejercita en el caso concreto ${ }^{18}$.

El contenido implícito se refiere a todas aquellas situaciones inherentes al acto administrativo, que no sean expresas, al tratarse de las disposiciones previstas por las normas específicas que regulan al acto administrativo; esto es que, aún y cuando no se especifique en la propia redacción del acto, se plasma el contenido de la norma de la cual emana y que, en última instancia, aún y cuando no sea invocado, constituye parte del objeto del acto administrativo.

\footnotetext{
273. ACOSTA ROMERO, Miguel. Teoría General del Derecho Administrativo, Primer Curso. 14. ed. Ciudad de México: Porrúa, 1999. p. 830. CASSAGNE, Juan Carlos. Derecho Administrativo. t. II. 7. ed. Buenos Aires: Lexis Nexis, 2002. p. 105.

14 Tal y cómo está regulado por la fracción II del artículo $3^{\circ}$ de la Ley Federal de Procedimiento Administrativo, y, de forma escueta, está señalado en la fracción IV del diverso artículo 38 del Código Fiscal de la Federación.

15 CASSAGNE, Juan Carlos. Derecho Administrativo. t. II. 7. ed. Buenos Aires: Lexis Nexis, 2002. p. 105.

16 No se debe perder de vista que tratándose del acto administrativo se tiene cierta tipicidad, es decir, en gran medida, los actos administrativos están diferenciados en los actos declarativos: permisos, licencias y autorizaciones, así como los actos registrales y, por otra parte, los llamados actos constitutivos: las concesiones, multas y en general, los actos derivados del derecho administrativo sancionador.

17 Cfr. GARRIDO FALLA, Fernando. Tratado de Derecho Administrativo. v. I. 13. ed. Madrid:Tecnos, 2002. p. 595.

18 Cfr. SANTAMARÍA PASTOR, Juan Alfonso. Principios de Derecho Administrativo. vol. II. 3. ed. Madrid: Ceura, 2002. p. 151.
} 
Por último, el contenido eventual, en palabras de Santamaría Pastor: "admite la posibilidad de incorporar determinaciones accesorias no previstas normativamente en la medida en que las mismas viabilicen la constitución de una situación jurídica que, sin la misma, habría de ser denegada"19. En pocas palabras, nos referimos pues a situaciones como la condición, el modo y el término.

La idea fundamental que subyace a las posturas antes expuestas sobre el objeto del acto administrativo, se integra por dos características esenciales, que no deben confundirse con el acto de fundamentar y motivar: a) el fundamento $y, b$ ) el motivo.

El fundamento refiere a la norma atributiva y la norma habilitante, que proporcionan los instrumentos normativos necesarios para su actuar a la Administración. Por ello, el efecto jurídico concreto tiene su base en, como lo señala Hans Kelsen20, en un sistema dinámico normativo, que se integra a partir de un sistema establecido en la Constitución, la legislación positiva, la normatividad distinta de la ley, y por supuesto, que todo tiene su origen en un esquema de principios generales como supralegales.

Así, para que el objeto del acto administrativo pueda concretarse se requiere que tenga un fundamento en la norma (insistimos, no debemos de confundirlo con la obligación que tiene la autoridad de transcribir en el acto administrativo el fundamento aplicable al caso concreto). Se trata de la obligación de que la actuación administrativa efectivamente cuente con un fundamento normativo específico.

Por otra parte, el motivo se identifica con la llamada verdad material, es decir, la realidad que se impone y obliga a la Administración a actuar. En otras palabras, el motivo es la realidad que se impone frente a la norma jurídico-administrativa. Se trata de un ejercicio donde la realidad se debe de imponer sobre la norma, y no tratar de adecuarla a la norma.

Ahora bien, por lo que ve al elemento formal, el profesor mexicano Miguel Acosta Romero señala que la forma: "constituye la manifestación material objetiva en que se plasma el acto administrativo para el efecto de que pueda ser apreciada por los sujetos pasivos o percibida a través de los sentidos"21.

El elemento formal del acto administrativo refiere al revestimiento que lo envuelve, es decir, a la sujeción de las formas en cuanto a su génesis y emisión. En un sistema jurídico como el mexicano, en gran medida materializa a la seguridad jurídica consagrada constitucionalmente y que todo acto de autoridad debe resguardar.

Complementando lo anterior, Marienhoff menciona que la forma refiere a la manera en la que se expresa un acto administrativo, sin que se confunda con el objeto o

\footnotetext{
19 lbidem.

20 Cfr. KELSEN, Hans. Teoría General del Derecho y del Estado. Trad. Eduardo García Maynez. 5. reimp. Ciudad de México: UNAM, 1995. p. 129-134.

21 ACOSTA ROMERO, Miguel. Teoría General del Derecho Administrativo, Primer Curso. 14. ed. Ciudad de México: Porrúa, 1999. p. 830.
} 
contenido del propio acto, al tratarse de su manifestación o exteriorización del mismo. Por ello, la forma se traduce en: a) la sujeción de la Administración Pública a la legalidad $y, b)$ que el particular vea sus derechos esenciales respetados. ${ }^{22}$

En este sentido, Gamero Casado y Fernández Díaz señalan que el elemento formal: "hace referencia a los requisitos formales que se imponen para la elaboración y producción de un acto administrativo. En el derecho Administrativo, el cumplimiento de las formas por parte de la Administración es especialmente exigido - principio de formas tasadas-, a diferencia de lo que sucede con el derecho privado, en el que impera el principio de libertad de forma."23

Así, dentro del elemento formal podemos distinguir, al menos, a los siguientes: a) el procedimiento, b) la forma en sentido estricto, c) la fundamentación y, d) la motivación. En cuanto al primero de estos elementos, en palabras del profesor argentino Roberto Dromi: "El procedimiento es en rigor respecto de la voluntad administrativa lo que el acueducto al agua, el conducto por el que transita -en nuestro caso- en términos de derecho, la actuación administrativa."24

El procedimiento es un presupuesto de existencia del acto administrativo, en cuanto que consiste en la previsibilidad de la actuación administrativa. Es una materialización de la seguridad jurídica en los actos de la autoridad administrativa, pues garantiza que la autoridad, al momento de emitir sus actos y resoluciones, está perfectamente ajustado a una serie de pasos a seguir, previamente regulados en ley Ley Federal de Procedimiento Administrativo, y que permitan al administrado, ejercer un derecho de audiencia durante el desarrollo del procedimiento y por tanto, garantizar el correcto resultado del acto administrativo.

No es gratuito que se pueda afirmar que no existe acto sin procedimiento, ni procedimiento sin acto.

Por su parte, aunque resulte obvio, la forma en sentido estricto se refiere a que todo acto administrativo deberá estar consagrado por escrito. Abundando un poco, las actuaciones administrativas procedimentales que preceden al acto administrativo, así como el acto administrativo mismo, deben estar plasmados por escrito, en lengua española25. Es importante destacar que por expresión escrita, en el derecho mexicano,

\footnotetext{
22 Cfr. MARIENHOFF, Miguel S. Tratado de derecho administrativo. t. II. 4. ed. Buenos Aires: Abeledo-Perrot, 2003. p. 266-268.

23 GAMERO CASADO, Eduardo; FERNÁNDEZ RAMOS, Severiano. Manual Básico de Derecho Administrativo. Madrid: Tecnos, 2008. p. 380.

24 DROMI, Roberto. El procedimiento administrativo. Buenos Aires: Ciudad Argentina, 1999. p. 30.

25 De conformidad a lo dispuesto por el artículo 271 del Código Federal de Procedimientos Civiles de aplicación supletoria a la Ley Federal de Procedimiento Administrativo, en términos de su artículo 1. Sin embargo, por lo menos en teoría no podemos descartar la posibilidad de que el acto administrativo (y su procedimiento, deba estar escrito además en alguna otra lengua de las reconocidas por el derecho mexicano, en términos de la Ley General de Educación, así con su respectiva traducción al español, tratándose de administrados cuyo idioma no sea el castellano.
} 
debemos de entender que se trata de una expresión en papel, o bien, por medios electrónicos 26 .

El último aspecto del elemento formal se refiere a la fundamentación y la motivación de todo acto administrativo. Así, como introducción a este punto, la Constitución mexicana señala textualmente: "Artículo 16. Nadie puede ser molestado en su persona, familia, domicilio, papeles o posesiones, sino en virtud de mandamiento escrito de la autoridad competente, que funde y motive la causa legal del procedimiento."27

Es importante señalar que el sentido que se utiliza de la fundamentación y motivación, aunque a rango constitucional no está limitada a un mero aspecto formal, y de alguna u otra manera podríamos inferir que se refiere también al fundamento y al motivo, consideramos que bajo ésta última perspectiva, se refiere más bien al elemento objetivo, y aún así, el texto del artículo 16 se refiere a la fundamentación y motivación como características que debe tener el acto por escrito, por lo que entonces podemos entenderlo en una referencia expresa a la forma.

En esta línea de pensamiento, complementando lo anterior, los profesores españoles Gallego Anabitarte y Menéndez Rexach señalan que: "debe distinguirse entre los motivos del acto y la motivación del acto, de tal manera que todo acto administrativo ha de basarse en unos motivos, pero la motivación lo que supone es la exigencia formal de que se expresen, se enuncien, las razones que sirven de fundamental a la decisión." 28

\footnotetext{
26 Hoy en día, encontramos que cada vez más se desarrolla el llamado e-government en México, de tal forma que una serie de trámites actualmente se pueden desahogar de forma electrónica. Esto ha sido particularmente utilizado en la materia tributario, sin embargo, también vemos la existencia del juicio contencioso administrativo en línea; los procedimientos licitatorios en línea, mediación en material de protección al consumidor en forma virtual, etc. Con el fin de ilustrar el peso de esta circunstancia, acudimos a la Tesis Aislada 2a.XCVII/2007, emitida por la Segunda Sala de la Suprema Corte de Justicia de la Nación. SEMANARIO JUDICIAL DE LA FEDERACIÓN. México. Novena Época. Tomo XXVI. Agosto de 2007. p. 638. Cuyo rubro y cuerpo señalan textualmente:
}

"FIRMA ELECTRÓNICA AVANZADA. EL HECHO DE QUE EL CÓDIGO FISCAL DE LA FEDERACIÓN NO ESTABLEZCA SU DEFINICIÓN NO VIOLA LA GARANTÍA DE LEGALIDAD.- El artículo 17-D del Código Fiscal de la Federación establece que cuando las disposiciones fiscales obliguen a presentar documentos, éstos deberán ser digitales y contener una firma electrónica avanzada del autor, salvo los casos previstos en el propio precepto, y que para esos efectos deberá contarse con un certificado que confirme el vínculo entre un firmante y los datos de creación de una "firma electrónica avanzada", expedido por el Servicio de Administración Tributaria cuando se trate de personas morales y por un prestador de servicios de certificación autorizado por el Banco de México cuando se trate de personas físicas, mediante el cumplimiento de ciertos requisitos, entre ellos, el de la comparecencia del interesado o de su apoderado o representante legal en caso de personas morales, con la finalidad de acreditar su identidad. De lo anterior se concluye que no se viola la garantía de legalidad contenida en el artículo 16 de la Constitución Política de los Estados Unidos Mexicanos, por el hecho de que el Código Fiscal de la Federación no establezca una definición particular de lo que debe entenderse por "firma electrónica avanzada", pues del indicado numeral 17-D se advierte el propósito perseguido con ésta, el cual, además de identificar al emisor de un mensaje como su autor legítimo, como si se tratara de una firma autógrafa, garantiza la integridad del documento produciendo los mismos efectos que las leyes otorgan a los documentos con firma autógrafa, teniendo el mismo valor probatorio; lo anterior, en razón de que la firma electrónica avanzada está vinculada a un certificado expedido por una autoridad, en este caso, por el Servicio de Administración Tributaria, en el que constan los datos del registro respectivo."

27 MÉXICO (País). Constitución Política de los Estados Unidos Mexicanos, vigente al 25 de octubre de 2017.

28 GALLEGo ANABITARTE, Alfredo; MENÉNDEZ REXACH, Ángel. Acto y Procedimiento Administrativo. Madrid: Marcial Pons, 2000. p. 200. 
Así, claramente podemos hacer la distinción entre el motivo (elemento objetivo, causa del acto administrativo) y la motivación (obligación de expresar dichos motivos en el acto administrativo).

Para los profesores argentinos Guido Santiago Tawil y Laura Mercedes Monti, la motivación es: "La exteriorización o expresión de los motivos o razones que han llevado al autor del acto a adoptarlo [...] la medida de los motivos y su determinación resulta incidida, a su vez, por otro elemento del acto administrativo: la finalidad."29

En pocas palabras, la motivación se traduce en la obligación de la autoridad al momento de emitir su acto administrativo, de externalizar su justificación o motivos de dicha emisión en el caso concreto, y esta obligación no es soslayable de ninguna manera, tanto por mandato constitucional, como por mandato legal.

Concluyendo este punto, la obligación constitucional de fundamentar el acto administrativo se refiere a la obligación o carga para la autoridad de expresar o externalizar en el acto administrativo los fundamentos aplicables al caso concreto, es decir, el fundamento (elemento objetivo) da la fuerza de la ley a la actuación administrativa, pero esto por sí mismo no resulta suficiente, pues es necesario que se exprese dicho fundamento en el acto, es decir, la fundamentación debe estar contenida en el acto ${ }^{30}$.

Por último, por lo que ve al elemento teleológico, donde se halla finalidad del acto administrativo, tenemos que señalar que se trata de un punto de difícil apreciación y juicio. Muchas son las disparidades al respecto entre los autores ${ }^{31}$ y en el caso

29 TAWIL, Guido Santiago; MONTI, Laura Mercedes. La motivación del acto administrativo. Buenos Aires: Depalma, 1998. p. 1.

30 Desde hace varios años, existen diversos criterios jurisprudenciales que señalan la obligación de que el acto administrativo contenga debidamente expresados los fundamentales legales de la actuación de la autoridad, simplemente como ilustración de este punto, invocamos la Tesis de Jurisprudencia 57/2001, emitida por la Segunda Sala de la Suprema Corte de Justicia de la Nación. SEMANARIO JUDICIAL DE LA FEDERACIÓN. México. Novena Época. T. XIV. Noviembre de 2001. p. 31. con la voz y cuerpo: "COMPETENCIA DE LAS AUTORIDADES ADMINISTRATIVAS. EN EL MANDAMIENTO ESCRITO QUE CONTIENE EL ACTO DE MOLESTIA, DEBE SEÑALARSE CON PRECISIÓN EL PRECEPTO LEGAL QUE LES OTORGUE LA ATRIBUCIÓN EJERCIDA Y, EN SU CASO, LA RESPECTIVA FRACCIÓN, INCISO Y SUBINCISO.- De lo dispuesto en la tesis de jurisprudencia P./J. 10/94 del Tribunal Pleno de la Suprema Corte de Justicia de la Nación, publicada en la Gaceta del Semanario Judicial de la Federación, Número 77, mayo de 1994, página 12, de rubro: “COMPETENCIA. SU FUNDAMENTACIÓN ES REQUISITO ESENCIAL DEL ACTO DE AUTORIDAD.", así como de las consideraciones en las cuales se sustentó dicho criterio, se desprende que la garantía de fundamentación consagrada en el artículo 16 de la Constitución Política de los Estados Unidos Mexicanos, lleva implícita la idea de exactitud y precisión en la cita de las normas legales que facultan a la autoridad administrativa para emitir el acto de molestia de que se trate, al atender al valor jurídicamente protegido por la exigencia constitucional, que es la posibilidad de otorgar certeza y seguridad jurídica al particular frente a los actos de las autoridades que afecten o lesionen su interés jurídico y, por tanto, asegurar la prerrogativa de su defensa, ante un acto que no cumpla con los requisitos legales necesarios. En congruencia con lo anterior, resulta inconcuso que para estimar satisfecha la garantía de la debida fundamentación, que establece dicho precepto constitucional, por lo que hace a la competencia de la autoridad administrativa para emitir el acto de molestia es necesario que en el documento que se contenga se invoquen las disposiciones legales, acuerdo o decreto que otorgan facultades a la autoridad emisora y, en caso de que estas normas incluyan diversos supuestos, se precisen con claridad y detalle, el apartado, la fracción o fracciones, incisos y subincisos, en que apoya su actuación; pues de no ser así, se dejaría al gobernado en estado de indefensión, toda vez que se traduciría en que éste ignorara si el proceder de la autoridad se encuentra o no dentro del ámbito competencial respectivo por razón de materia, grado y territorio y, en consecuencia, si está o no ajustado a derecho. Esto es así, porque no es permisible abrigar en la garantía individual en cuestión ninguna clase de ambigüedad, ya que su finalidad consiste, esencialmente, en una exacta individualización del acto de autoridad, de acuerdo a la hipótesis jurídica en que se ubique el gobernado en relación con las facultades de la autoridad, por razones de seguridad jurídica."

31 Desde la misma termología, por ejemplo, Miguel Acosta Romero se refiere a la finalidad como el objeto indirecto del acto. Cfr. ACOSTA ROMERO, Miguel. Teoría General del Derecho Administrativo, Primer Curso. 14. ed. Ciudad de México: Porrúa, 1999. p. 829 y 830. 
del derecho mexicano, ha resultado poco explorada, ya sea por los autores o por los juzgadores.

Gamero Casado y Fernández Ramos señalan que la finalidad de la actuación administrativa está directamente dependiente a la finalidad conferida en la norma, esto es que, el legislativo, en base a su natural inclinación a servir al interés general, le dota o atribuye una serie de competencias y modos de actuar a la Administración, con el fin de garantizar ese servicio al interés general y que en el caso concreto, lo somete a las propias finalidades establecidas en la norma de la cual emana dicha atribución 32.

La fracción III del artículo 3 de la Ley Federal de Procedimiento Administrativo señala que el acto administrativo debe cumplir con la finalidad contenida en la norma de la cual emana, sin que se pueda perseguir otra distinta. En ese sentido, se debe recurrir a las normas sustantivas de la materia (competencia económica, ambiental, propiedad intelectual, etc.), las cuales establecen sus propias finalidades y éste debe ser la guía del actuar administrativo.

También es importante destacar el papel que la exposición de motivos juega para efectos de determinar la finalidad que persiguen determinadas atribuciones normativas de las autoridades administrativas, de tal forma que, aún si la ley en su cuerpo no específica ni aporta alguna una pista de cuál deba ser la finalidad perseguida por una determinada norma, el operador jurídico puede recurrir a la exposición de motivos para ajustar su actuación a dichas finalidades 33 .

\footnotetext{
32 Cfr. GAMERO CASADO, Eduardo; FERNÁNDEZ RAMOS, Severiano. Manual Básico de Derecho Administrativo. Madrid: Tecnos, 2008. p. 379

33 En este sentido, la Tesis XXII.3o.1 A emitida por el Tercer Tribunal Colegiado del Vigésimo Segundo Circuito. SEMANARIO JUDICIAL DE LA FEDERACIÓN. México. Décima Época. T. IV. L. 24. Noviembre de 2015. p. 3657. Al respecto, nos ilustra este punto: "TASA ADICIONAL" O "SOBRETASA". SI EN LA EXPOSICIÓN DE MOTIVOS, EN LOS DICTÁMENES O EN LA LEY DE HACIENDA MUNICIPAL DE QUE SE TRATE NO SE EXPRESAN CONSIDERACIONES ESPECÍFICAS DESTINADAS A JUSTIFICAR LA RAZONABILIDAD DE SU IMPOSICIÓN PARA SATISFACER EL FIN EXTRAFISCAL QUE PERSIGUE, EL ÓRGANO DE CONTROL CONSTITUCIONAL CARECE DE ELEMENTOS PARA PODER DETERMINAR LA CONSTITUCIONALIDAD O NO DEL PRECEPTO QUE LA PREVÉ, CUANDO SU MONTO SEA SUPERIOR AL DE LA TASA BASE.- En las jurisprudencias 1a./J. 46/2005 y 2a./J. 126/2013 (10a.), emitidas por la Primera y Segunda Salas de la Suprema Corte de Justicia de la Nación, de rubros: "FINES EXTRAFISCALES. CORRESPONDE AL ÓRGANO LEGISLATIVO JUSTIFICARLOS EXPRESAMENTE EN EL PROCESO DE CREACIÓN DE LAS CONTRIBUCIONES." " "IMPUESTO ADICIONAL. LOS ARTÍCULOS 119 A 125 DE LA LEY GENERAL DE HACIENDA MUNICIPAL DEL ESTADO DE MORELOS QUE LO PREVÉN, VIOLAN EL PRINCIPIO DE PROPORCIONALIDAD TRIBUTARIA.", respectivamente, así como en las ejecutorias de las que derivaron se establece, entre otras cosas, que las contribuciones han sido clasificadas, tanto en la doctrina como en los diversos sistemas impositivos, de distintas formas, entre ellas, como "sobretasas" o "tasas adicionales", que son las que recaen sobre algunos de los impuestos previamente establecidos y tienen, como característica fundamental, que los recursos obtenidos se destinan a un fin específico; es decir, constituyen un porcentaje adicional (segundo nivel) que aprovecha la existencia de un nivel impositivo primario, respecto del cual comparte los mismos elementos constitutivos del tributo; esto es, solamente se aplica un porcentaje adicional a la base gravable, por considerar que la capacidad contributiva gravada es suficiente para soportar ambas cargas tributarias. Asimismo, que el legislador está constitucionalmente facultado para establecer a un impuesto primario una tasa adicional, pero ello debe responder a fines extrafiscales, supuesto en el cual tendrá la obligación constitucional ineludible de justificarlos expresamente -mediante argumentos o razones específicas suficientes- ya sea en la exposición de motivos, en los dictámenes o en la misma ley. Con base en los lineamientos anotados, se concluye que si en la exposición de motivos, en los dictámenes o en la ley de hacienda municipal de que se trate no se expresan consideraciones específicas destinadas a justificar la razonabilidad de la imposición de la "tasa adicional" o "sobretasa" para satisfacer el fin extrafiscal que persigue, el órgano de control constitucional carece de elementos para poder determinar la constitucionalidad o no del precepto que la prevé, cuando su monto sea superior al de la tasa base; omisión que lleva a que la disposición reclamada infrinja el artículo 115, fracción IV, inciso a), de la Constitución Política de los Estados Unidos Mexicanos."
} 
Si el elemento teleológico del acto administrativo está directamente vinculado a la finalidad que se persigue con la actuación administrativa, y ésta se desprende en principio de la norma habilitante, pues el legislador establece dicha finalidad acorde a una finalidad superior de interés general, es importante destacar que aun cuando el legislador nos dejase en una zona de penumbra en cuanto a los fines de una norma, es posible para los operadores jurídicos, detectar dicha finalidad a partir de los fines mismos del sistema jurídico y al respecto, señala el profesor español Jesús Leguina Villa:

La determinación de los fines públicos y de las necesidades colectivas que han de ser satisfechas por los aparatos administrativos es una decisión que corresponde en cada caso al legislador en cuanto depositario de la soberanía popular y representante de la voluntad del cuerpo electoral. La Administración [... d debe servir eficazmente a los intereses generales, y para ello cuenta con el arsenal de las potestades que el legislador pone en sus manos, pero no puede sustituir o modificar los objetivos o fines públicos que la ley le señala caso por caso. El interés público concreto, en razón del cual se justifica el ejercicio de cada potestad, resulta sí indisponible para la Administración, de suerte que si ésta se aparta del fin cuyo cuidado se le encomienda, sustituyendo con su propia voluntad la opción teleológica realizada por el legislador, viene a colocarse en la posición constitucional de éste último, subvirtiendo el equilibrio de poderes y degradando la supremacía de la ley. La Administración puede sin duda colaborar con el legislador en la tarea de precisar los fines a alcanzar, si a ello es llamada por aquél, pero carece de poder para ignorarlos. 34

Por tanto y a modo de conclusión de este breve apartado, la finalidad del acto administrativo, no es otra cosa sino la adecuación de la actuación en sí a la racionalidad de la norma y los fines establecidos por el legislador en la norma habilitante, acorde al sistema y valores concretos que están, no solo a rango constitucional, sino que se desprenden de los principios rectores, los cuales son de orden supralegal 35 .

\section{EL FUNDAMENTO CONSTITUCIONAL DEL ACTO ADMINISTRATIVO}

La Constitución recoge los principios y establece las reglas jurídicas 36 que marcan el parámetro de actuación de los órganos supremos del Estado, sus modos de

\footnotetext{
34 Prólogo en CHINCHILLA MARÍN, Carmen. La desviación de Poder. 2. ed. Madrid:Thomson Civitas, 2004. p. 12.

35 A mayor abundamiento sobre este particular, Cfr. BÉJAR RIVERA, Luis José. Fundamentos de derecho administrativo. Ciudad de México: Tirant lo Blanch, 2012.

36 Los principios poseen una fuerza deóntica intrínseca y su validez depende de su propio contenido y naturaleza -que precede al derecho positivo-; además pueden cumplirse o respetarse en mayor o menor medida, al ser mandatos de optimización que impactan de manera cualitativa a todo el sistema normativo. Las reglas surgen con el derecho positivo y tienen razón de ser
} 
creación y sus relaciones con los otros órganos, al igual que el ejercicio del poder estatal37. Las disposiciones constitucionales deben ser obedecidas, aplicadas, cumplidas y respetadas en todo acto de autoridad, para dar cumplimiento al principio de supremacía constitucional.

Por conducto del principio de supremacía constitucional, como menciona Jorge Carpizo: "se dispone que la Constitución es la ley suprema, es la norma cúspide de todo el orden jurídico, es el alma y la savia que nutre y unifica el derecho, es la base de todas las instituciones y el ideario de un pueblo" 38 .

Por ello, gracias al principio de supremacía constitucional se impone a la Constitución como la norma de mayor jerarquía del sistema normativo que: "preside y otorga la unidad al conjunto de normas que integran los diversos niveles del orden jurídico de un Estado"39.

La cualidad de supremacía es inherente a toda Constitución, al permitirle imponerse sobre cualquier potestad o institución jurídica. Por tanto, en: “lo normativo nada se le reconoce como superior a ésta. Constituye, organiza, faculta, regula actuaciones, limita y prohíbe" 40 .

La Constitución juega un papel primordial para el ramo administrativo, porque, como sostiene Eberhard Schmidt-Assmann, siguiendo a la célebre frase atribuida a Fritz Werner: "El Derecho Administrativo es el Derecho Constitucional concretizado", término que corresponde, como lo menciona Martin Ibler, con una: “[...] expresión muy conocida en Alemania, que desde los comienzos de la República Federal de Alemania en los años cincuenta del siglo XX (que) describe la conexión entre el Derecho administrativo y el Derecho constitucional [...]"41, que supone una complementación entre ellos porque: "[...] la legislación administrativa ha de interpretarse «a la luz» de las garantías constitucionales [...]"42.

Rodríguez-Arana menciona que el Derecho Administrativo es el Derecho Constitucional concretizado porque "tiene unos fundamentos 'per se' independientes y

\footnotetext{
sólo por éste, pues tienen una fuerza deóntica externa que depende de la voluntad del legislador, debido a que su validez y razonabilidad dependen del acto legislativo que las genera. Cfr. CIANCIARDO, Juan. Principios y Reglas: Una Aproximación desde los Criterios de Distinción. Boletín Mexicano de Derecho Comparado, Ciudad de México, año XXXVI, n 108. sept./dec. 2003. p. 891- 906.

37 Cfr. JELLINEK, Georg. Teoría General del Estado. Trad. Fernando de los Ríos. 3. reimpr. Ciudad de México: Fondo de Cultura Económica, 2000. p. 457.

38 CARPIZO, Jorge. Estudios Constitucionales. 8. ed. Ciudad de México: Porrúa, 2012. p. 1.

39 HARO, Ricardo. Manual de Derecho Constitucional. Córdoba: Advocatus, 2011. p. 115.

40 ARTEAGA NAVA, Elisur. Derecho Constitucional. 4. ed. Ciudad de México: Oxford, 2013. p. 3.

41 IBLER, Martin. Pasado y presente de la relación entre el Derecho constitucional y el Derecho administrativo en Alemania. Cuadernos constitucionales de la Cátedra Fadrique Furió Ceriol, Valencia, n. 50/51, 2005. p. 5.

42 SCHMIDT-ASSMANN, Eberhard. Cuestiones fundamentales sobre la reforma de la Teoría General del Derecho Administrativo. In: BARNÉS VÁZQUEZ, Javier (Ed.). Innovación y Reforma en el Derecho Administrativo. 2. ed. Madrid: Global Law Press, 2012. p. 57.
} 
autónomos como Ciencia jurídica. Lo que pasa es que necesita un contexto de operatividad que viene definido por el propio Ordenamiento constitucional"43.

Por lo anterior es que, pese a que el Derecho Administrativo necesite de normas legales y reglamentarias que habiliten los mandatos constitucionales, tales normas no pueden ni deben entenderse de manera aislada, sino en función de las disposiciones constitucionales que los fundamenten de manera originaria, porque éstas "no sólo disciplina[n] las formas de producción legislativa, sino que impone[n] también a ésta prohibiciones y obligaciones de contenido"44, como sostiene Luigi Ferrajoli.

Al igual que el resto de categorías e instituciones del derecho administrativo, por virtud del principio de supremacía constitucional, el acto administrativo encuentra su fundamento originario en la Constitución, al contener las bases normativas de todos los elementos del acto administrativo, que deben replicarse y respetarse en el resto de normas legales y reglamentarias, so pena de control constitucional.

Y es que toda Constitución, al ser suprema, se impone sobre las demás normas secundarias que integran el sistema jurídico, condicionando su contenido y alcance. Por ello, en virtud del mencionado principio, la Constitución se erige como el ordenamiento primario que sienta las bases del derecho administrativo, rama que se construye y opera a partir del texto fundamental.

Así, en la Constitución mexicana se contiene el fundamento originario del elemento subjetivo, al establecer que los actos administrativos deben ser expedidos por autoridad competente 45 , estableciendo el reparto originario de competencias, entre los distintos niveles de gobierno 46 .

De la misma manera, el fundamento del elemento objetivo descansa en todas las disposiciones constitucionales que se relacionen con el acto administrativo en cuestión, porque, para que su objeto sea plenamente lícito, el acto debe abstenerse de violentar lo previsto en la Constitución, ya sea sin actualizar las prohibiciones constitucionales 47 o sin afectar derechos fundamentales ${ }^{48}$, por mencionar algunos ejemplos.

Por lo que hace al elemento formal de los actos administrativos, la Constitución mexicana establece que tales actos deben constar por escrito, en los que las autoridades competentes los fundamenten y motiven 49 . Ello, al margen de las formalidades que el texto constitucional impone a los distintos actos procedimentales, como, por ejem-

\footnotetext{
43 RODRÍGUEZ-ARANA, Jaime. Concepto y presupuestos del derecho administrativo constitucional. Revista de la Facultad de Derecho de México, Ciudad de México, vol. XLI, n. 175-176-177, 1991. p. 210.

44 FERRAJOLI, Luigi. Pasado y futuro del Estado de Derecho. In: CARBONELL, Miguel (comp.). Neoconstitucionalismo(s). 4. ed. Madrid: Trotta, 2009. p. 18.

45 Cfr. Art. 16. MÉXICO (País). Constitución Política de los Estados Unidos Mexicanos, vigente al 25 de octubre de 2017.

46 Cfr. Art. 124. Idem.

47 Como la relativa a que las autoridades administrativas solo pueden imponer arresto hasta por 36 horas. Cfr. Art. 21. Idem.

48 Cfr. Art. 10. Idem.

49 Cfr. Art. 16. Idem.
} 
plo, los derivados de los oficios comisorios, con los que las autoridades ordenan visitas de verificación para ejercer sus facultades de comprobación 50 .

En cuanto al elemento teleológico del acto administrativo, reconocemos que no existe mención expresa en la Constitución mexicana, entendiendo que la finalidad de los actos administrativos es precisamente la finalidad que le marque, por una parte la norma positiva, y por la otra, la finalidad que se desprende del sistema por sí mismo, podemos afirmar que la Constitución, enmarca precisamente, a la finalidad de las actuaciones administrativas, e incluso, la podríamos derivar de la propia redacción del párrafo primero del artículo 1 de la misma, el cual señala:

Artículo 10. En los Estados Unidos Mexicanos todas las personas gozarán de los derechos humanos reconocidos en esta Constitución y en los tratados internacionales de los que el Estado Mexicano sea parte, así como de las garantías para su protección, cuyo ejercicio no podrá restringirse ni suspenderse, salvo en los casos y bajo las condiciones que esta Constitución establece.

Lo anterior, sin duda, refiere a la clásica concepción del derecho administrativo del profesor español Gónzalez Navarro, que lo concibe como el derecho del poder público para la libertad y, como adiciona el profesor Rodríguez-Arana, para la solidaridad ciudadana. Es precisamente ésta, donde descansa la finalidad de los actos administrativos, desde una óptica constitucional.

\section{LOS MECANISMOS DE CONTROL CONSTITUCIONAL DEL ACTO ADMINISTRATIVO}

Ahora bien, para garantizar que el principio de supremacía constitucional se respete en toda actuación estatal y que se dote de operatividad y de aplicación al ordenamiento fundamental, es que la Constitución prevé diversos mecanismos de control que tienen por objeto invalidar o inaplicar, según corresponda, las normas jurídicas que la contravengan.

Para Manuel Aragón, el control constitucional es un elemento inseparable del concepto Constitución que: "no forma parte únicamente de un concepto 'político' de Constitución, como sostenía Schmitt, sino de su concepto jurídico, de tal manera que sólo si existe control de la actividad estatal puede la Constitución desplegar su fuerza normativa" 51 .

\footnotetext{
50 Cfr. Idem.
}

51 ARAGÓN, Manuel. Constitución, Democracia y Control. Ciudad de México: Instituto de Investigaciones Jurídicas 2002 . p. 81. 
Después de la reforma constitucional del año 2011 en materia de derechos humanos, la Constitución y su supremacía son tutelados por diversos mecanismos de control constitucional. La facultad de defensa del ordenamiento constitucional no se circunscribe de manera exclusiva a la competencia del Poder Judicial de la Federación, sino que se extiende a todos los órganos estatales, atendiendo al modelo mixto de control constitucional que rige en México52.

En la resolución a la consulta varios 912/2010, el Pleno reconoció de manera expresa que la Constitución mexicana está protegida por cuatro tipos de control constitucional53: control concentrado o directo, control por determinación constitucional específica, control difuso y control por interpretación conforme al principio pro persona.

El modelo de control constitucional tiene injerencia directa en el derecho administrativo mexicano 54 porque ahora todos los operadores jurídicos que ejercen función administrativa, al igual que los que la controlan, tienen facultades de controlar las normas que aplican, sea interpretándolas a la luz de la Constitución, inaplicándolas o invalidándolas, según corresponda.

De los cuatro tipos de control que existen en México tres son los que tienen una relación directa e inmediata con el control del fundamento constitucional de los actos administrativos: control concentrado, por conducto del juicio de amparo directo o indirecto; control difuso, por medio del juicio contencioso administrativo; $y$, finalmente, control por interpretación conforme al principio pro personae, aplicable a la expedición del propio acto y a la resolución del recurso administrativo.

El control concentrado o directo es realizado por los jueces de amparo del Poder Judicial de la Federación, mediante los siguientes mecanismos: controversias constitucionales55, acciones de inconstitucionalidad56, amparo indirecto (del que puede emanar una declaratoria general de inconstitucionalidad57) y amparo directo. Con excepci-

52 Cfr. Resolución del Expediente Varios 912/2010, del Pleno de la Suprema Corte de Justicia de la Nación. In: COSsíO DíAZ, José Ramón; MEJÍA GARZA, Raúl; ROJAS ZAMUDIO, Laura Patricia. El Caso Radilla, estudios y documentos. Ciudad de México: Porrúa, 2012. p. 876-880.

53 Idem.

54 Para mayor abundamiento, véase: SALAZAR MUÑOZ, Rodrigo. Neoconstitucionalismo: ¿nuevo paradigma del Derecho Administrativo?: La constitucionalización del Derecho Administrativo mexicano. Madrid: Editorial Académica Española, 2016.

55 “De las controversias constitucionales que, con excepción de las que se refieran a la materia electoral, se susciten entre: a) La Federación y un Estado o el Distrito Federal; b) La Federación y un municipio; c) El Poder Ejecutivo y el Congreso de la Unión aquél y cualquiera de las Cámaras de éste o, en su caso, la Comisión Permanente, sean como órganos federales o del Distrito Federal [...] la resolución de la Suprema Corte de Justicia las declare inválidas, dicha resolución tendrá efectos generales cuando hubiera sido aprobada por una mayoría de por lo menos ocho votos". Art. 105. F. I. MÉXICO (País). Constitución Política de los Estados Unidos Mexicanos, vigente al 25 de octubre de 2017.

56 "De las acciones de inconstitucionalidad que tengan por objeto plantear la posible contradicción entre una norma de carácter general y esta Constitución. Las resoluciones de la Suprema Corte de Justicia sólo podrán declarar la invalidez de las normas impugnadas, siempre que fueren aprobadas por una mayoría de cuando menos ocho votos." Art. 105. F. II. Idem.

57 “Cuando los órganos del Poder Judicial de la Federación establezcan jurisprudencia por reiteración en la cual se determine la inconstitucionalidad de una norma general, la Suprema Corte de Justicia de la Nación lo notificará a la autoridad emisora. Transcurrido el plazo de 90 días naturales sin que se supere el problema de inconstitucionalidad, la Suprema Corte de Justicia de la Nación emitirá, siempre que fuere aprobada por una mayoría de cuando menos ocho votos, la declaratoria general de 
ón de los juicios de amparo, las resoluciones de los mecanismos de control restantes tienen efectos erga omnes, siempre que sean aprobados por ocho de los once ministros que integran el Pleno de la Suprema Corte de Justicia de la Nación.

El juicio de amparo es el mecanismo de tutela del fundamento constitucional de los actos administrativos. Por su conducto, cualquier persona que se vea afectada por un acto administrativo que se estime inconstitucional puede acudir ante los órganos del Poder Judicial de la Federación para combatirlos. De hecho, tal y como se señaló en líneas precedentes, el juicio de amparo antecede con mucho, al juicio contencioso administrativo en nuestro país.

De resultar procedente, el amparo otorga la protección de la justicia de la unión, declarando la ilegalidad del acto administrativo, provocando su invalidez, restituyendo a la persona afectada en el goce de los derechos fundamentales le fue violentados, y garantizando la no repetición del acto58.

Resulta conveniente destacar que, al control concentrado también se le denomina directo, porque la Constitución mexicana otorga una competencia específica de control constitucional a los órganos del Poder Judicial de la Federación, y a que se ejerce en procesos cuya Litis principal versa sobre la constitucionalidad de normas secundarias, sean generales o individualizadas, como ocurre con los actos administrativos.

En otro orden de ideas, ya que los tribunales administrativos son órganos jurisdiccionales, les compete ejercer el control difuso de constitucionalidad, mediante la inaplicación de las leyes y normas reglamentarias que contravengan la Constitución o los derechos humanos reconocidos en ésta en un acto administrativo.

En palabras de Héctor Fix-Zamudio, el control difuso de constitucionalidad consiste en: "la facultad atribuida a todos los jueces para declarar en un proceso concreto la inaplicabilidad de las disposiciones legales secundarias que sean contrarias a la Constitución y con efectos sólo para las partes que han intervenido en esa controversia."59

Se le denomina difuso porque la competencia de control constitucional se reparte entre el universo de órganos jurisdiccionales del Estado mexicano que no realizan funciones de control concentrado o por determinación constitucional específica, entre los que se encuentran los tribunales de lo contencioso administrativo, quienes deben ejercerlo en tres pasos, partiendo de la interpretación conforme al principio pro personae60:

\footnotetext{
inconstitucionalidad, en la cual se fijarán sus alcances y condiciones en los términos de la ley reglamentaria." Art. 107. F. II. Idem. 58 Cfr. Art. 107, F I. Idem. Al respecto, véase: SALAZAR MUÑOZ, Rodrigo. Algunas Consideraciones sobre la Declaratoria General de Inconstitucionalidad. Revista Académica de la Facultad de Derecho de la Universidad la Salle, Ciudad de México, año XI, n. 22. ene. 2014. p. 97-116.

59 FIX-ZAMUDIO, Héctor; VALENCIA CARMONA, Salvador. Derecho constitucional mexicano y comparado. 5. ed. México: Porrúa, 2007. p. 206.

60 Cfr. Resolución del expediente varios 912/2010. Op. Cit.
} 
El primer paso consiste en realizar una interpretación conforme en sentido amplio61. Al respecto, los tribunales administrativos deben interpretar el ordenamiento jurídico a la luz de los derechos humanos reconocidos en la Constitución y en los tratados internacionales suscritos por México, favoreciendo en todo tiempo a las personas con la protección más amplia.

El segundo paso radica en ejercer una interpretación conforme en sentido estricto62, partiendo de la constitucionalidad de las leyes y normas reglamentarias aplicables, siempre que existan distintas interpretaciones jurídicamente válidas. En cuyo caso, los tribunales de lo contencioso administrativo deben preferir la interpretación que provoque una mayor protección de los derechos humanos reconocidos en la Constitución.

Finalmente, de no poderse llevar a cabo los pasos anteriores, los tribunales de lo contencioso administrativo inaplicarán las leyes y normas reglamentarias, cuando contravengan los fundamentos constitucionales de los actos administrativos, ejerciendo plenamente el control constitucional inaplicando las disposiciones que contravengan los fundamentos supremos de los actos administrativos.

Finalmente, en relación al control por interpretación conforme al principio pro personae, debemos señalar que, acorde con el mandato constitucional previsto en el artículo 1, las autoridades administrativas deben ejercerlo mediante la interpretación de las normas que integran el ordenamiento jurídico a la luz de la Constitución, aplicando la interpretación que más favorezca a la persona63, sin que conlleve la inaplicación de las normas legales o reglamentarias aplicables, ya que:

La supremacía normativa de la Constitución no se manifiesta sólo en su aptitud de servir como parámetro de validez de todas las demás normas jurídicas, sino también en la exigencia de que tales normas, a la hora de ser aplicadas, se interpreten de acuerdo con los preceptos constitucionales; de forma que, en caso de que existan varias posibilidades de interpretación de la norma en cuestión, se elija aquella que mejor se ajuste a lo dispuesto en la Constitución. 64

\footnotetext{
61 Consiste en realizar una interpretación conforme en sentido amplio, en la que los órganos jurisdiccionales interpreten el ordenamiento jurídico a la luz de los derechos humanos reconocidos en la Constitución y en los tratados internacionales en los que el Estado Mexicano sea parte, favoreciendo a la persona con la protección más amplia. Cfr. Idem.

62 Que parte de la constitucionalidad de las normas aplicables, cuando existen distintas interpretaciones jurídicamente válidas. En cuyo caso, la interpretación conforme al principio pro personae se realiza al preferir la interpretación que provoque la mayor protección de los derechos humanos reconocidos en la Constitución y en los tratados internacionales. Cfr. Idem.

63 Por cierto, acorde al tradicional principio de derecho administrativo de la interpretación más favorable al particular.

64 Según afirmó la Primera Sala de la Suprema Corte de Justicia de la Nación en la Tesis denominada "INTERPRETACIÓN CONFORME. NATURALEZA Y ALCANCES A LA LUZ DEL PRINCIPIO PRO PERSONA", en la Tesis 1a. CCCXL/2013. SEMANARIO JUDICIAL DE LA FEDERACIÓN. México. Décima Época. T. I. Diciembre de 2013. p. 530.
} 
Y es que, la supremacía constitucional no sólo opera ni se agota al momento de creación de las normas jurídicas secundarias, cuyo contenido debe ajustarse al de la Constitución, sino que también opera como parámetro interpretativo ineludible al momento de aplicar las normas jurídicas de nivel inferior65. Al respecto, la Primera Sala de la Suprema Corte de Justicia de la Nación ha sostenido que:

Este principio de interpretación conforme de todas las normas del ordenamiento a la Constitución, reiteradamente utilizado por esta Suprema Corte de Justicia de la Nación, es una consecuencia elemental de la concepción del ordenamiento como una estructura coherente, como una unidad o contexto. Asimismo, hoy en día, el principio de interpretación conforme de todas las normas del ordenamiento a la Constitución, se ve reforzado por el principio pro persona, contenido en el artículo 1o. de la Constitución Política de los Estados Unidos Mexicanos, el cual obliga a maximizar la interpretación conforme en aquellos escenarios en los cuales, dicha interpretación permita la efectividad de los derechos fundamentales de las personas frente al vacío legislativo que puede provocar una declaración de inconstitucionalidad de la norma. 66

En razón de lo anterior, arribamos a la conclusión de que las facultades de las autoridades administrativas se han constitucionalizado, porque todas ellas deben, al realizar los actos procedimentales, al emitir los actos administrativos o al controlarlos, mediante los recursos administrativos, interpretar las normas legales y reglamentarias aplicables a la luz de la Constitución.

Resulta conveniente destacar, respecto del referido control, que en el fallo del expediente varios 912/2010, el Pleno de la Suprema Corte de Justicia de la Nación se opuso a que las autoridades administrativas realicen inaplicación de leyes y normas reglamentarias, circunscribiendo el ámbito de aplicación del control a la realización de la interpretación conforme al principio pro personae, tanto en sentido amplio como en estricto.

\section{CONCLUSIONES}

A partir de la identificación de los elementos esenciales del acto administrativo es que podemos detectar específicamente cuáles son regulados (o quasi regulados desde el ámbito constitucional). Tratándose del derecho mexicano, tomando en

\footnotetext{
65 Al respecto véase: SALAZAR MUÑOZ, Rodrigo. Un acercamiento al paradigma neoconstitucionalista. Revista del Instituto de la Judicatura Federal, Ciudad de México, Núm. Especial, 2014.p. 320-354.

66 Cfr. Tesis 1a. CCCXL/2013, De rubro: “INTERPRETACIÓN CONFORME. NATURALEZA Y ALCANCES A LA LUZ DEL PRINCIPIO PRO PERSONA". SEMANARIO JUDICIAL DE LA FEDERACIÓN. México. Décima Época. T. I. Diciembre de 2013. p. 530.
} 
consideración el propio texto constitucional, así como el comportamiento de los jueces, se puede señalar que ha proliferado el control estricto de la legalidad, fundando sus fallos en gran medida en lo dispuesto por el artículo 16 de la Constitución mexicana, sin embargo, podemos apreciar que el resto de los elementos esenciales, en mayor o menor medida, cuentan con un basamento constitucional que debe respetarse en función del principio de supremacía.

Por lo anterior, la Administración Pública no se encuentra limitada a lo que marcan leyes de las distintas materias, como la Ley Especial o la Ley Federal de Procedimiento Administrativo, que regulan los requisitos de los actos administrativos, al deber tomar en consideración lo previsto en las disposiciones constitucionales que resulten directamente aplicables al caso concreto, so pena de control constitucional.

Asimismo, el juzgador, sea judicial o contencioso, no se encuentra limitado a hacer un mero control de la legalidad de los actos administrativos y de sus fundamentos legales y reglamentarios, sino que debe pronunciarse sobre la constitucionalidad de los mismos, bajo las reglas que marca el modelo mexicano de control constitucional.

La reforma constitucional del año 2011, en materia de derechos humanos, ha marcado la evolución del modelo mexicano de control constitucional, de uno concentrado hacia uno mixto, en el que participan también los tribunales de lo contencioso administrativo, con el control difuso, y las autoridades administrativas, con el control por interpretación conforme, que vincula a la Administración Pública con el texto constitucional, que debe respetar al emitir y ejecutar sus actos administrativos.

Actualmente, los diversos mecanismos de control constitucional continúan desarrollándose y evolucionando. Cada día encontramos nuevos pronunciamientos jurisprudenciales emanados del Poder Judicial de la Federación que impulsan la actuación de los jueces ordinarios para pronunciarse respecto de la constitucionalidad de los actos que juzgan, al igual que de los fundamentos aplicables.

\section{REFERENCIAS}

ACOSTA ROMERO, Miguel. Teoría General del Derecho Administrativo, Primer Curso. 14. ed. Ciudad de México: Porrúa, 1999.

ARAGÓN, Manuel. Constitución, Democracia y Control. Ciudad de México: Instituto de Investigaciones Jurídicas 2002.

ARTEAGA NAVA, Elisur. Derecho Constitucional. 4. ed. Ciudad de México: Oxford, 2013.

BÉJAR RIVERA, Luis José. El acto administrativo y su finalidad. Ciudad de México: Porrúa, 2016.

BÉJAR RIVERA, Luis José. Fundamentos de derecho administrativo. Ciudad de México: Tirant lo Blanch, 2012. 
BÉJAR RIVERA, Luis José. La dualidad jurisdiccional en materia administrativa en México. In: RODRÍGUEZ-ARANA MUÑOZ, Jaime; VÁZQUEZ IRIZARRY, William; RODRÍGUEZ MARTÍN-RETORTILLO, María, (Coords.) Contenciosos administrativos en Iberoamérica. t. I. San Juan: Universidad de Puerto Rico, 2015.

CARPIZO, Jorge. Estudios Constitucionales. 8. ed. Ciudad de México: Porrúa, 2012.

CASSAGNE, Juan Carlos. Derecho Administrativo. t. II. 7. ed. Buenos Aires: Lexis Nexis, 2002.

CIANCIARDO, Juan. Principios y Reglas: Una Aproximación desde los Criterios de Distinción. Boletín Mexicano de Derecho Comparado, Ciudad de México, año XXXVI, n 108. sept./dec. 2003.

CHINCHILLA MARÍN, Carmen. La desviación de Poder. 2. ed. Madrid:Thomson Civitas, 2004.

COSSÍO DÍAZ, José Ramón; MEJÍA GARZA, Raúl; ROJAS ZAMUDIO, Laura Patricia. El Caso Radilla, estudios y documentos. Ciudad de México: Porrúa, 2012.

DROMI, Roberto. El procedimiento administrativo. Buenos Aires: Ciudad Argentina, 1999.

FERRAJOLI, Luigi. Pasado y futuro del Estado de Derecho. In: CARBONELL, Miguel (comp.). Neoconstitucionalismo(s). 4. ed. Madrid:Trotta, 2009.

FIX-ZAMUDIO, Héctor; VALENCIA CARMONA, Salvador. Derecho constitucional mexicano y comparado. 5. ed. México: Porrúa, 2007.

FRAGA, Gabino. Derecho Administrativo. 28. ed. Ciudad de México: Porrúa, 1989.

GALLEGo ANABITARTE, Alfredo; MENÉNDEZ REXACH, Ángel. Acto y Procedimiento Administrativo. Madrid: Marcial Pons, 2000.

GAMERO CASADO, Eduardo; FERNÁNDEZ RAMOS, Severiano. Manual Básico de Derecho Administrativo. Madrid: Tecnos, 2008.

GARANT, Patrice. Droit administratif. 6. ed. Cowansville: Éditions Yvon Blais, 2010.

GARRIDO FALLA, Fernando. Tratado de Derecho Administrativo. v. I. 13. ed. Madrid: Tecnos, 2002.

HARO, Ricardo. Manual de Derecho Constitucional. Córdoba: Advocatus, 2011.

IBLER, Martin. Pasado y presente de la relación entre el Derecho constitucional y el Derecho administrativo en Alemania. Cuadernos constitucionales de la Cátedra Fadrique Furió Ceriol, Valencia, n. 50/51, 2005.

JELLINEK, Georg. Teoría General del Estado. Trad. Fernando de los Ríos. 3. reimpr. Ciudad de México: Fondo de Cultura Económica, 2000.

KELSEN, Hans. Teoría General del Derecho y del Estado. Trad. Eduardo García Maynez. 5. reimp. Ciudad de México: UNAM, 1995. 
MARIENHOFF, Miguel S. Tratado de derecho administrativo. t. II. 4. ed. Buenos Aires: Abeledo -Perrot, 2003.

MÉXICO. Código Federal de Procedimientos Civiles, vigente al 25 de octubre de 2017.

MÉXICO. Código Fiscal de la Federación, vigente al 25 de octubre de 2017.

MÉXICO. Constitución Política de los Estados Unidos Mexicanos, vigente al 25 de octubre de 2017.

MÉXICO. Ley Federal de Procedimiento Administrativo, vigente al 25 de octubre de 2017.

MÉXICO. Ley General de Educación, vigente al 25 de octubre de 2017.

NAVA NEGRETE, Alfonso. Derecho administrativo mexicano. 2. ed. Ciudad de México: FCE, 2001. PÉREZ DAYÁN, Alberto. Teoría General del Acto Administrativo. Ciudad de México: Porrúa, 2003. RODRÍGUEZ-ARANA, Jaime. Concepto y presupuestos del derecho administrativo constitucional. Revista de la Facultad de Derecho de México, Ciudad de México, vol. XLI, n. 175-176-177, 1991. ROLDÁN XOPA, José. Derecho Administrativo. Ciudad de México: Oxford University Press, 2008. SALAZAR MUÑOZ, Rodrigo. Algunas Consideraciones sobre la Declaratoria General de Inconstitucionalidad. Revista Académica de la Facultad de Derecho de la Universidad la Salle, Ciudad de México, año Xl, n. 22. ene. 2014.

SALAZAR MUÑOZ, Rodrigo. Neoconstitucionalismo: ¿nuevo paradigma del Derecho Administrativo?: La constitucionalización del Derecho Administrativo mexicano. Madrid: Editorial Académica Española, 2016.

SALAZAR MUÑOZ, Rodrigo. Un acercamiento al paradigma neoconstitucionalista. Revista del Instituto de la Judicatura Federal, Ciudad de México, Núm. Especial, 2014.

SANTAMARÍA PASTOR, Juan Alfonso. Principios de Derecho Administrativo. vol. Il. 3. ed. Madrid: Ceura, 2002.

SCHMIDT-ASSMANN, Eberhard. Cuestiones fundamentales sobre la reforma de la Teoría General del Derecho Administrativo. In: BARNÉS VÁZQUEZ, Javier (Ed.). Innovación y Reforma en el Derecho Administrativo. 2. ed. Madrid: Global Law Press, 2012.

TAWIL, Guido Santiago; MONTI, Laura Mercedes. La motivación del acto administrativo. Buenos Aires: Depalma, 1998. 